\title{
Regulatory Properties of Brain Glutamate Decarboxylase (GAD): The Apoenzyme of GAD Is Present Principally as the Smaller of Two Molecular Forms of GAD in Brain
}

\author{
David L. Martin,, ${ }^{1,2}$ Sandra B. Martin, ${ }^{1}$ Susan J. Wu, ${ }^{1}$ and Noel Espina ${ }^{1,2}$ \\ 'Wadsworth Center for Laboratories and Research, New York State Department of Health, Albany, New York 12201 and \\ 2Department of Environmental Health and Toxicology, SUNY, Albany, New York 12201
}

The apoenzyme of glutamate decarboxylase [enzyme without bound cofactor, pyridoxal 5'-phosphate (pyridoxal-P)] serves as a reservoir of inactive glutamate decarboxylase (GAD) that can be activated when additional GABA synthesis is required. We have investigated which of two molecular forms of GAD is present as apoenzyme in synaptosomes and in cortex, caudate nucleus, hippocampus, and cerebelIum of rat brain. Endogenous glutamate apodecarboxylase (apoGAD) was labeled by incubating extracts of synaptosomes or punches of each region with ${ }^{32} \mathrm{P}$-pyridoxal-P, followed by reduction with $\mathrm{NaBH}_{4}$, to link covalently the ${ }^{32} \mathrm{P}$ pyridoxal-P to GAD. Proteins were separated by SDS-PAGE. Punches from all four brain regions and forebrain synaptosomes contained two forms of GAD with apparent $M, s$ of 63 and $65 \mathrm{kDa}$ as identified by immunoblotting with four antiGAD sera. Punches and synaptosomes contained a major ${ }^{32} \mathrm{P}$. pyridoxal-P-labeled band with an apparent $M$, of $63 \mathrm{kDa}$ that was stained on immunoblots by the antiGAD serum 1440 and the monoclonal antibody GAD-6, and a minor labeled band at $65 \mathrm{kDa}$ that was stained by the 1440, 6799, and K2 antisera. Synaptosomes contained remarkably few other strongly labeled proteins, but punches contained several other labeled bands. Three additional lines of evidence indicate that the labeled 63-kDa protein is apoGAD: (1) it was purified by immunoaffinity chromatography with the GAD-1 monoclonal antibody; (2) it yielded one major labeled peptide when digested with chymotrypsin, and that peptide appeared identical in peptide-mapping experiments to the labeled active-site peptide isolated from chromatographically prepared rat brain GAD; and (3) its labeling was selectively blocked by 4-deoxypyridoxine 5 -phosphate, a competitive inhibitor of the binding of pyridoxal-P to GAD. The labeled 65-kDa protein also appears to be apoGAD as indicated by immunoblotting and inhibition of labeling by 4-deoxypyridoxine $5^{\prime}$-phosphate. Labeling of the 63-kDa protein

\footnotetext{
Received Dec. 26, 1990; revised Mar. 29, 1991; accepted Apr. 3, 1991.

This work was supported by Grant MH35664 from the U.S. Public Health Service, Department of Health and Human Services. We thank Drs. A. J. Tobin and D. Kaufman (UCLA) for the K2 antiserum, Dr. R. Greenspan (Roche Institute for Molecular Biology, Nutley, NJ) for the 6799 antiserum, and Dr. D. Gottlieb (Washington University, St. Louis, MO) for the GAD-1 and GAD-6 monoclonal antibodies. The 1440 antiserum was provided by the National Institute of Mental Health, where it was produced by Drs. W. Oertel, M. Tappaz, and D. Schmechel under the direction of Dr. I. Kopin.

Correspondence should be addressed to David L. Martin, Ph.D., Wadsworth Center for Laboratories and Research, P.O. Box 509, Albany, NY 12201-0509. Copyright $(\mathcal{C} 1991$ Society for Neuroscience $0270-6474 / 91 / 112725-07 \$ 03.00 / 0$
}

was strongest in the hippocampus and weakest in cerebellum. The results indicate that the majority apoGAD in brain is associated with the smaller of two forms of GAD and suggest that GAD is unusual, if not unique, in being present in large amounts as apoenzyme.

GABA, the major inhibitory neurotransmitter in brain, is synthesized principally by glutamate decarboxylase (GAD; EC 4.1.1.15), which requires the cofactor pyridoxal 5'-phosphate (pyridoxal-P) for activity. It has been known for many years that the majority of GAD in brain is present as apoenzyme, which serves as a reservoir of inactive GAD that can be activated by the cofactor when additional GABA synthesis is required (Miller et al., 1977, 1980; Itoh and Uchimura, 1981). Enzymological studies have shown that interconversion of the apo- and holoenzyme states of GAD occurs by a series of reactions catalyzed by GAD and is a highly regulated process (revicwed by Martin, 1987).

Several groups have reported that multiple forms of GAD are present in brain (Spink and Martin, 1983; Spink et al., 1983, 1987; Denner and Wu, 1985; Gottlieb et al., 1986; Kaufman et al., 1986; Legay et al., 1986, 1987; Chang and Gottlieb, 1988), and differences have been found among the forms in their interactions with pyridoxal-P (Denner and Wu, 1985; Spink et al., 1985, 1987; Erlander et al., 1991; Kaufman et al., 1991). Although the apparent molecular weights of the forms of GAD differ somewhat among reports (possibly because of differences in electrophoretic conditions and procedures), it is clear that brain contains at least two forms of GAD in the $59-67-\mathrm{kDa}$ range that differ by $2-4 \mathrm{kDa}$ (Gottlieb et al., 1986; Kaufman et al., 1986, 1991; Legay et al., 1986, 1987; Chang and Gottlieb, 1988; Martin et al., 1990a). In keeping with this pattern, cloning studies have identificd $m$ RNAs that encode forms of GAD with predicted molecular weights of approximately $65 \mathrm{kDa}$ (Erlander et al., 1991) and $67 \mathrm{kDa}$ (Kaufman et al., 1986; Kobayashi et al., 1987; Katarova et al., 1990; Wyborski et al., 1990), termed $\mathrm{GAD}_{65}$ and $\mathrm{GAD}_{67}$, respectively. All of these studies, taken together, suggest that the individual forms of GAD are regulated differently and raise an important question: Which of the forms of GAD accounts for the large amount of apoGAD known to be present in brain?

We recently have shown that ${ }^{32} \mathrm{P}$-pyridoxal-P can be used to label the active site of GAD (Martin et al., 1990a). In the work reported here, we have used active-site labeling with ${ }^{32} \mathrm{P}$-pyridoxal-P to identify apoGAD in synaptosomes and brain tissue. The results show that apoGAD is present principally as $\mathrm{GAD}_{65}$, 
which has an apparent $M$, of $63 \mathrm{kDa}$ under our electrophoretic conditions.

A preliminary report of this work has appeared previously (Martin et al., 1990b).

\section{Materials and Methods}

Procedures and conditions for SDS-polyacrylamide gel electrophoresis, chymotryptic digestion, high-performance liquid chromatography on sulfopropyl and $\mathrm{C} 18$ reverse-phase columns, immunoaffinity chromatography on the GAD-1 column, determining apparent molecular weights from dried electrophoretic gels, and preparing ${ }^{32} \mathrm{P}$-pyridoxal- $\mathrm{P}$ have been described previously (Martin et al., 1990a).

Synaptosomes were prepared as described by Loscher et al. (1985). To prepare brain punches, adult rats $(\approx 225 \mathrm{gm})$ were decapitated into liquid $\mathrm{N}_{2}$, and the heads were allowed to freeze for about $15 \mathrm{~min}$. The heads were allowed to warm to near $0^{\circ} \mathrm{C}$, and the brain was dissected by carving away the flesh and bone. Coronal slices $(1 \mathrm{~mm})$ were prepared by using a specially constructed slicer cooled with dry ice. Bilateral punches $(2 \mathrm{~mm}$ diameter) were taken from cerebral cortex, caudate nucleus, hippocampus, and cerebellar vermis from slices corresponding to plates 9-12, 9-12, 27-30, and 52-55, respectively, of Palkovits and Brownstein (1988). The brain, slices, and punches remained frozen throughout the procedure, which required about $2 \mathrm{hr}$.

To label GAD in synaptosomes, $50 \mu \mathrm{l}$ of synaptosomal suspension ( $0.9 \mathrm{mg}$ protein) was added to $600 \mu \mathrm{l}$ of a labeling medium containing $100 \mathrm{~mm}$ HEPES, $1 \mathrm{~mm}$ 2-aminoethylisothiouronium bromide (AET), $0.1 \%$ Triton $\mathrm{X}-100$, and $5 \mu \mathrm{Ci}$ of ${ }^{32} \mathrm{P}$-pyridoxal- $\mathrm{P}(\mathrm{pH} 7.2)$ and was allowed to incubate at $37^{\circ} \mathrm{C}$. In some experiments, the solution also contained various concentrations of 4-deoxypyridoxine 5 -phosphate (deoxypyridoxine-P). At the appropriate time, 50- $\mu$ l samples were removed and added to $50 \mu \mathrm{l}$ of $20 \mathrm{~mm} \mathrm{HCl}$ (to bring the $\mathrm{pH}$ to 6.3 ) containing $2 \% 1$-octanol and immediately reduced by adding $18 \mathrm{~mm}$ $\mathrm{NaBH}_{4}$. After a 40-min reaction period on ice, the samples were prepared for electrophoresis by adding SDS, $\beta$-mercaptoethanol (final concentrations, $1 \%$ ), and sucrose (final concentration, 20\%). Autoradiograms were prepared after the gel was dried. The same procedure was used for samples to be chromatographed on the GAD-1 column, except that the ${ }^{32} \mathrm{P}$-pyridoxal-P was increased to $50 \mu \mathrm{Ci}$, the sample size was larger $(650 \mu \mathrm{l})$, and the $\mathrm{NaBH}_{4}$-treated sample was loaded directly on the GAD-1 immunoaffinity column before being prepared for SDSpolyacrylamide gel electrophoresis. GAD in punches was labeled by a similar procedure. Labeling medium $(100 \mu \mathrm{l})$ was added to a microcentrifuge tube containing a punch, and the punch was immediately dispersed by sonication with a $50-\mathrm{W}$ high-intensity ultrasonic processor (Sonics and Materials, Inc., Danbury, CT). After the appropriate incubation period, $\mathrm{HCl}$ was added to bring the $\mathrm{pH}$ to 6.3 , and the ${ }^{32} \mathrm{P}$ pyridoxal-P adducts were reduced with $\mathrm{NaBH}_{4}$. Labeled extracts of six punches were pooled for chromatography on the GAD-1 immunoaffinity column. For punches to be used for chymotryptic digests, the labeling medium contained $100 \mu \mathrm{Ci}$ of ${ }^{32} \mathrm{P}$.

For immunoblotting, proteins were transferred to Immobilon-P (Millipore Corp.) transfer membrane by the procedure of Towbin et al. (1979) in a Hoefer TE42 Transphor apparatus operated at $100 \mathrm{~V}$ for $45 \mathrm{~min}$. The Immobilon sheet was blocked with $0.1 \%$ Tween 20 in Trisbuffered saline ( $\mathrm{pH} 7.5$ ) and treated to reduce nonspecific staining by using an avidin/biotin blocking kit (Vector). The blot was then treated with the primary antibodies by using an Immunetics Miniblotter, which makes it possible to stain the proteins from one electrophoretic lane with more than one antiserum. We used four antisera to identify GAD on immunoblots. The 6799 (Katarova et al., 1990) and K2 antisera (Kaufman et al., 1991) were raised against the larger form $\left(\mathrm{GAD}_{67}\right)$ of mouse and cat GAD (as produced by bacterial expression systems), and each recognizes the higher-molecular-weight form of GAD. The GAD-6 monoclonal antibody (Chang and Gottlieb, 1988) recognizes the lowermolecular-weight form. This antibody was raised against a $59-\mathrm{kDa}$ form of GAD; a partial amino acid sequence of this enzyme was similar to the sequence predicted from the message for $\mathrm{GAD}_{65}$ and significantly different from that predicted from the message for $\mathrm{GAD}_{67}(\mathrm{M}$. Erlander and A. J. Tobin, personal communication). The 1440 antiserum (Oertel et al., $1981 \mathrm{a}, \mathrm{b}$ ) is widely used for GAD immunocytochemistry and stains the smaller form of GAD more intensely than the larger. The dilutions were K2, 1:5000; GAD-6, 1:800; 1440, 1:10,000; 6799, 1:3000. After incubation and washing, each lane was treated with the appropriate secondary antibody (biotinylated goat anti-rabbit $\mathrm{IgG}$, horse anti-mouse
IgG, or rabbit anti-sheep IgG; 1:1200) and then washed thoroughly. Color was developed by using the Vectastain ABC-alkaline phosphatase kit (Vector).

\section{Results}

We observed remarkably few intensely labeled proteins when synaptosomes were lysed in the presence of ${ }^{32} \mathrm{P}$-pyridoxal-P under conditions designed to label the active site of GAD and then analyzed by SDS-PAGE and autoradiography (Fig. 1). The apparent $M_{r}$ of one of the major labeled bands $(63 \pm 0.4 \mathrm{kDa} ; n$ =6) was the same as the $M_{r}$ of one of the forms of GAD previously purified in this laboratory (Martin et al., 1990a), while the $M_{r}$ of the other major labeled band was much smaller $(\approx 30 \mathrm{kDa})$. A much less intensely labeled band $\left(M_{r}=65 \pm 0.5\right.$ $\mathrm{kDa}$ ) was observed directly above the $63-\mathrm{kDa}$ band. Densitometric measurements indicated that the $63-\mathrm{kDa}$ band contained about $82 \%$ of the total radioactivity in the $63-$ and $65-\mathrm{kDa}$ proteins. The $30-\mathrm{kDa}$ band does not appear on most autoradiograms, because the gels were run for longer times to obtain greater separation of the individual molecular forms of GAD. Labeling of the $63-\mathrm{kDa}$ protein followed a time course that was virtually identical to that of purified rat brain GAD and was essentially complete after about 10 min of incubation with ${ }^{32} \mathrm{P}$ pyridoxal-P (Fig. $1 B$ ).

Because pyridoxal-P has a highly reactive carbonyl group, it can react with exposed amino groups and nonspecifically label proteins. To investigate the specificity of labeling, we examined the effect of deoxypyridoxine-P, a close structural analog of pyridoxal-P that lacks the carbonyl group. Deoxypyridoxine-P competitively inhibits the activation of apoGAD by pyridoxal-P and inhibits active-site labeling of GAD by ${ }^{32} \mathrm{P}$-pyridoxal-P (Martin et al., 1990a). Deoxypyridoxine-P strongly inhibited labeling of the $63-$ and $65-\mathrm{kDa}$ proteins, but had little if any effect on the minor labeled proteins in synaptosomes (Fig. 2) or the $30-\mathrm{kDa}$ band (data not shown). Labeling was inhibited by more than $50 \%$ at $30 \mu \mathrm{M}$ deoxypyridoxine-P and was complete at $300 \mu \mathrm{M}$. This concentration dependence is similar to that observed previously with purified GAD and is in the appropriate range given the concentration of pyridoxal-P and the relative dissociation constants for pyridoxal-P and deoxypyridoxine-P (Martin et al., 1990a).

We identified the position of each of the forms of GAD on the gels by immunoblotting with four antiGAD antibodies that recognize each form to various degrees (described in Materials and Methods). All four antibodies stained synaptosomal proteins, indicating that synaptosomes contain both molecularweight forms of GAD. The apparent $M_{r}$ of the higher-molecularweight band stained by the $\mathrm{K} 2$ and 6799 antisera was $2-3 \mathrm{kDa}$ higher than the apparent $M_{r}$ of the lower hand stained by the 1440 and GAD-6 antibodies (Fig. 2, inset). Autoradiography of the immunoblot showed that the intensely radioactive $63-\mathrm{kDa}$ protein corresponded exactly to the lower-molecular-weight form of GAD that is more strongly stained by the 1440 antiserum and the GAD-6 monoclonal antibody (i.e., $\mathrm{GAD}_{65}$ ). The 65$\mathrm{kDa}$ band that was less intensely labeled with ${ }^{32} \mathrm{P}$ corresponded exactly with the protein stained by the K2 and 6799 antisera (i.e., GAD 67 ; Fig. 2, inset).

The same pattern of immunostaining was observed when extracts of brain punches were stained with the four antibodies: K2 and 6799 stained a band with an apparent $M_{r}, 2-3 \mathrm{kDa}$ greater than that of the major protein stained by the 1440 and GAD-6 antibodies (Fig. 3A). 

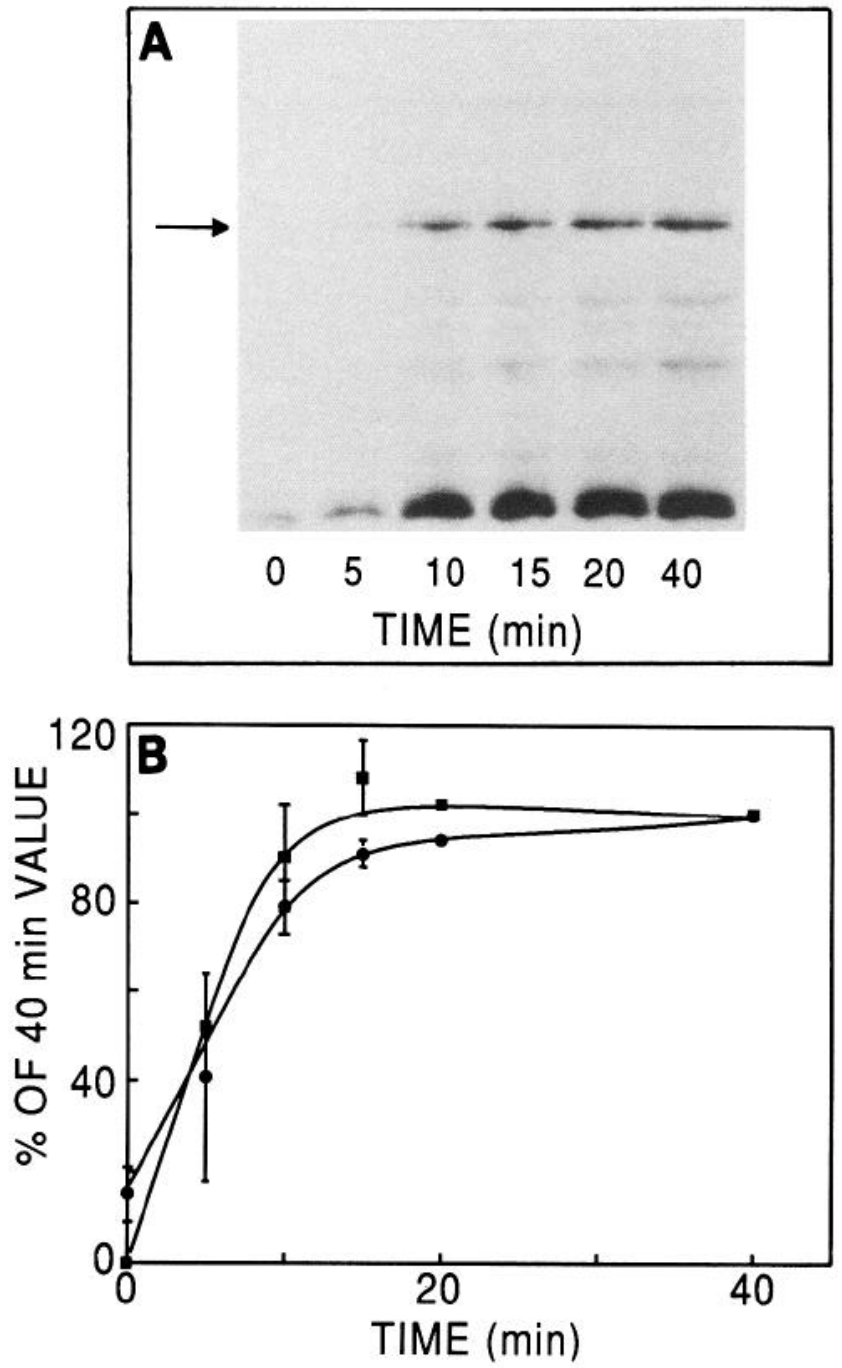

To identify which forms of GAD are present as apoenzyme in vivo, we labeled extracts of brain punches from rapidly frozen brain with ${ }^{32} \mathrm{P}$-pyridoxal-P. Rapid freezing was used to minimize the post-mortem activation of apoGAD (Miller et al., 1977) and the possibility of proteolytic degradation of the enzyme. We observed a more complex pattern of labeled proteins with brain punches than with synaptosomes (cf. Figs. 1, 3B). (The 30-kDa protein was intensely labeled in brain punches, as in synaptosomes, but was not retained on the gel illustrated in Fig. 3). The same proteins appeared to be labeled in all four regions, though the relative intensity of labeling of the individual proteins differed among the regions. This pattern was consistently observed in four independent experiments. The most intensely labeled protein had the same $M_{r}(63 \pm 0.4 \mathrm{kDa} ; n=7)$ as purified peakIII GAD (Martin et al., 1990a) and the heavily labeled band in synaptosomes and, furthermore, coincided exactly with the position of the GAD protein stained more strongly by the 1440 and GAD-6 antibodies (Fig. 3B, lower arrow). Thus, it was identified as $\mathrm{GAD}_{65}$. Similarly, a much less intensely labeled protein $\left(M_{r}=65.7 \pm 0.6 \mathrm{kDa}\right)$ coincided exactly with the position of $\mathrm{GAD}_{67}$ as identified by staining with the $\mathrm{K} 2$ and 6799 antisera (Fig. $3 B$, upper arrow). We attempted to estimate the relative amounts of radioactivity in the 63 - and $65-\mathrm{kDa}$ bands by densitometry, but the close spacing between the $65-\mathrm{kDa}$ band

Figure 1. Time course of labeling of synaptosomal proteins by ${ }^{32} \mathrm{P}-$ pyridoxal-P. A, Autoradiogram of an SDS-polyacrylamide gel. Synaptosomal extracts were incubated for the indicated times with ${ }^{32} \mathrm{P}$-pyridoxal-P, reduced with $\mathrm{NaBH}_{4}$, and analyzed by SDS-PAGE. The arrow indicates the $63-\mathrm{kDa}$ band. The labeled $65-\mathrm{kDa}$ protein is visible just above the $63-\mathrm{kDa}$ band. The labeled $30-\mathrm{kDa}$ protein is at the bottom of the gel. $B$, Comparison of the time courses of labeling of the $63-\mathrm{kDa}$ protein in synaptosomal extracts $(\square)$ and purified peak-III GAD from rat brain ( $(0)$. Labeled bands were cut from the gel, and radioactivity was measured by liquid scintillation counting. Error bars indicate SD.

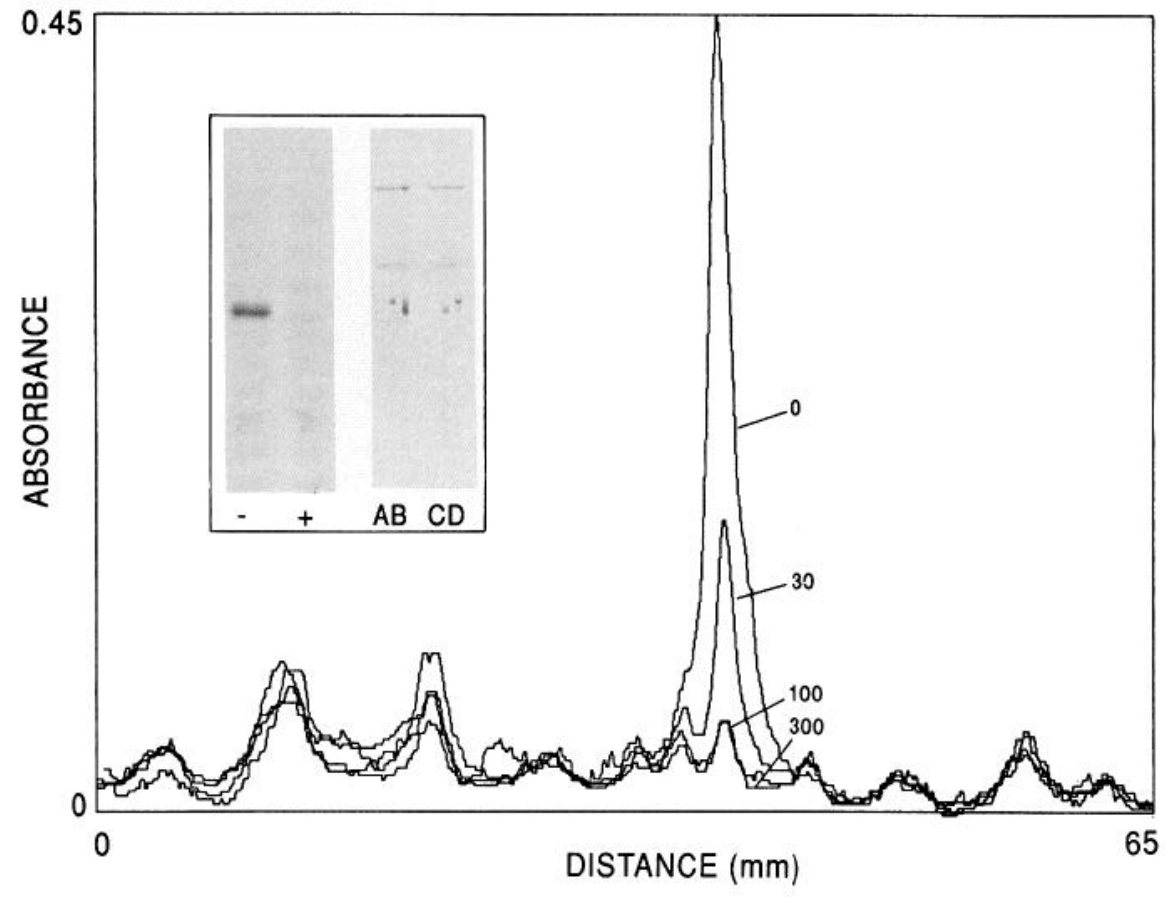

Figure 2. Deoxypyridoxine-P inhibits the labeling of the $63-\mathrm{kDa}$ protein in synaptosomal extracts. Densitometry scans of an autoradiogram of an SDS-polyacrylamide gel prepared from synaptosomal extracts labeled with ${ }^{32} \mathrm{P}$ pyridoxal-P in the absence and presence of the indicated concentrations (in $\mu \mathrm{M})$ of deoxypyridoxine-P. Inset, Autoradiogram (left) of immunoblot of an SDS-polyacrylamide gel of a synaptosomal extract labeled in the absence (-) and presence $(+)$ of $300 \mu \mathrm{M}$ deoxypyridoxine-P, and the immunoblot (right) stained with K2 (lane A), 1440 (lane B), GAD-6 (lane C), and 6799 (lane D) antibodies to GAD. On the autoradiogram, the dark band and the lighter band immediately above it are the 63- and $65-\mathrm{kDa}$ labeled proteins. 

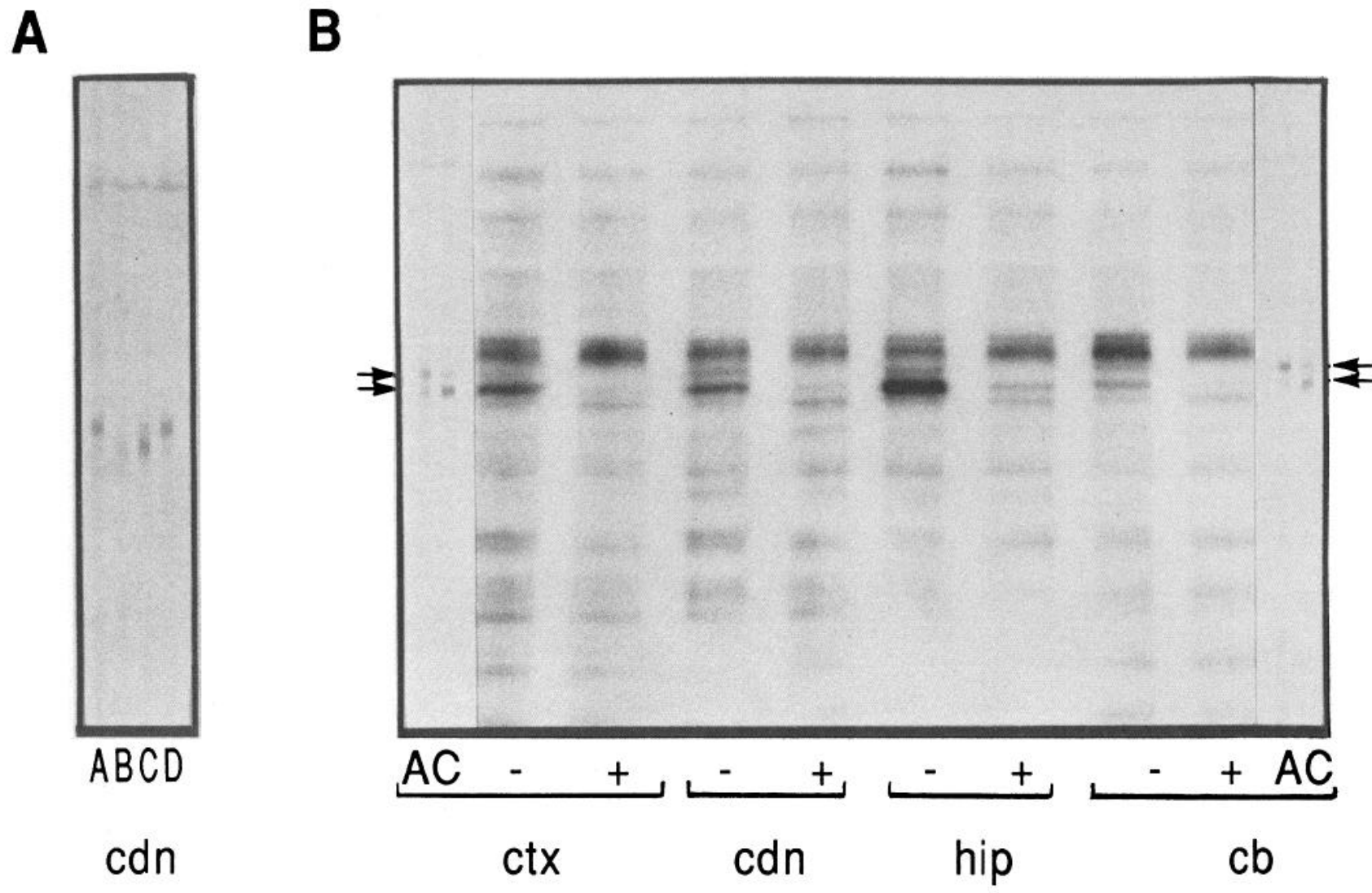

Figure 3. Immunoblotting and labeling with ${ }^{32} \mathrm{P}$-pyridoxal-P of tissue punches from four regions of rapidly frozen rat brain. $A$, Immunoblot of an SDS-polyacrylamide gel of caudate nucleus (cdn) stained with K2 (lane A), GAD-6 (lane B), 1440 (lane C), and 6799 (lane D) antiGAD sera. $B$, Autoradiograph of an immunoblot of extracts of cerebral cortex ( $c t x)$, caudate nucleus $(c d n)$, hippocampus (hip), and cerebellum $(c b)$ labeled with ${ }^{32} \mathrm{P}$-pyridoxal-P in the absence $(-)$ and presence $(+)$ of $300 \mu \mathrm{M}$ deoxypyridoxine-P. Lanes of the immunoblot of the cortex and cerebellum stained with the $\mathrm{K} 2(A)$ and $1440(C)$ antisera are aligned with the autoradiogram. Arrows indicate the 63- and 65-kDa bands. The 30-kDa protein was not retained on the gel.

and the intensely labeled bands above and below it on the autoradiograms prevented us from obtaining reasonably reliable integration of the individual bands. Nevertheless, visual inspection clearly showed that the $63-\mathrm{kDa}$ band contained far more than half of the label in each region. As in synaptosomes, the labeling of both the $63-$ and the $65-\mathrm{kDa}$ bands was strongly inhibited by deoxypyridoxine-P (Fig. 3B). Labeling of the 63$\mathrm{kDa}$ protein was greatest in hippocampal punches and least in cerebellar punches. Densitometric measurements showed that the heavily labeled bands at about $68-71 \mathrm{kDa}$ were unaffected by deoxypyridoxine-P.

To identify further the labeled proteins in the synaptosomal and hippocampal extracts, the labeled proteins were purified by immunoaffinity chromatography on a column prepared with the GAD-1 monoclonal antibody to GAD (Gottlieb et al., 1986; Martin et al., 1990a; Fig. 4). In each case, the eluate contained a single labeled protein with the same apparent $M_{r}$ as the major labeled band in the tissue extract and as purified labeled GAD.

In a previous study, we showed that chymotryptic digestion produces a single major labeled peptide from GAD that had been labeled in the active site with ${ }^{32} \mathrm{P}$-pyridoxal-P (Martin et al., 1990a). To determine if GAD in tissue extracts is labeled in the same position, we prepared chymotryptic digests of the labeled $63-\mathrm{kDa}$ bands from synaptosomes and hippocampal punches and analyzed them by HPLC (Fig. 5). The chromato- grams of the digests were almost superimposable, indicating that the same peptide was labeled in each case.

\section{Discussion}

Several groups have demonstrated the presence of multiple forms of GAD in the brains of rats and other species (Spink and Martin, 1983; Spink et al., 1983, 1987; Denner and Wu, 1985; Gottlieb et al., 1986; Kaufman et al., 1986, 1991; Legay et al., 1986, 1987; Chang and Gottlieb, 1988). Although the estimated molecular weights of the subunits differ somewhat among these reports, it is clear that brain contains at least two major forms of GAD that have subunits with apparent $M_{r} \mathrm{~s}$ in the range of 59-67 kDa that differ by 2-4 kDa (Gottlieb et al., 1986; Kaufman et al., 1986, 1991; Legay et al., 1986, 1987; Chang and Gottlieb, 1988; Martin et al., 1990a). In every case, these molecular weights were estimated by SDS-PAGE, and it appears likely that the differences in the absolute values of the molecular weights result from differences in electrophoretic procedures. This pair of proteins appears to be produced from two messages for GAD that have predicted subunit molecular weights of 65 and $67 \mathrm{kDa}\left(\mathrm{GAD}_{65}\right.$ and $\mathrm{GAD}_{67}$; Erlander et al., 1991). Because the absolute values of the molecular weights differ among reports and are therefore undependable as identifiers of the forms of $\mathrm{GAD}$, we have relied on immunoblotting with four antisera to identify the forms of GAD in rat brain. The $\mathrm{K} 2$ antiserum was 


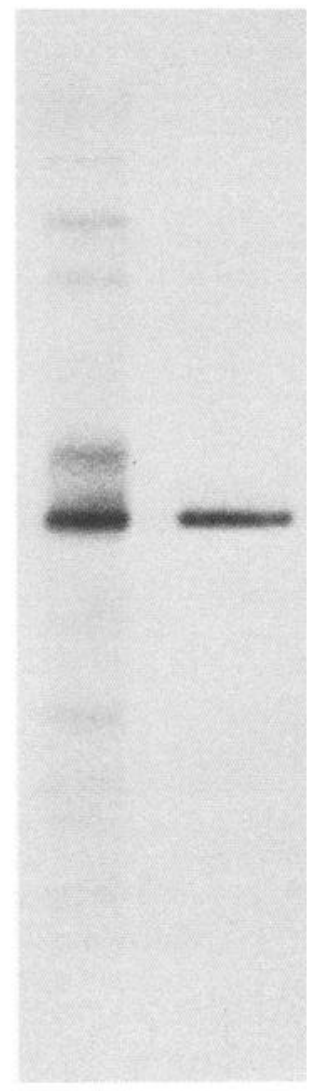

\section{A B}

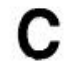

D

Figure 4. Autoradiogram of an SDS-polyacrylamide gel showing the immunoaffinity purification of ${ }^{32} \mathrm{P}$-labeled GAD. Hippocampal (lanes $A, B$ ) and synaptosomal (lanes $D, E$ ) extracts were labeled with ${ }^{32} \mathrm{P}$-pyridoxal-P and either analyzed directly by SDS-PAGE $(A, D)$ or purified by immunoaffinity chromatography on a GAD-1 anti-GAD column and then applied to the gel $(B, E)$. Lane $C$ contains purified peak-III GAD from rat brain (Martin et al., 1990a).

raised against bacterially expressed GAD from cat brain (Kaufman et al., 1991), and the 6799 antiserum was produced similarly from a cDNA for mouse brain GAD, which has a predicted amino acid sequence $95 \%$ identical to that predicted from the message for $\mathrm{GAD}_{67}$ from rat brain (Katarova et al., 1990). These two antisera more intensely stain the higher-molecular-weight form of GAD $\left(\mathrm{GAD}_{67}\right)$. GAD-6 is a monoclonal antibody raised against a 59-kDa form of GAD (Chang and Gottlieb, 1988), which has a sequence significantly different from that predicted from the message for the $67-\mathrm{kDa}$ form of GAD and appears to be a product of the message for the smaller form $\left(\mathrm{GAD}_{65}\right)$. It selectively stains the lower-molecular-weight form of GAD. The 1440 antiserum is used widely for GAD immunocytochemistry (Oertel et al., 1981a,b) and stains the lower-molecular-weight form of GAD more intensely than the higher-molecular-weight form.

The results presented here show that the great majority of the apoGAD in the cerebral cortex, caudate nucleus, hippocampus, cerebellum, and forebrain synaptosomes is accounted for by $\mathrm{GAD}_{65}$, one of two major forms of GAD in adult rat brain. (This form has an apparent $M_{r}$ of $\approx 63 \mathrm{kDa}$ under our electrophoresis conditions). Several lines of evidence indicate that the labeled

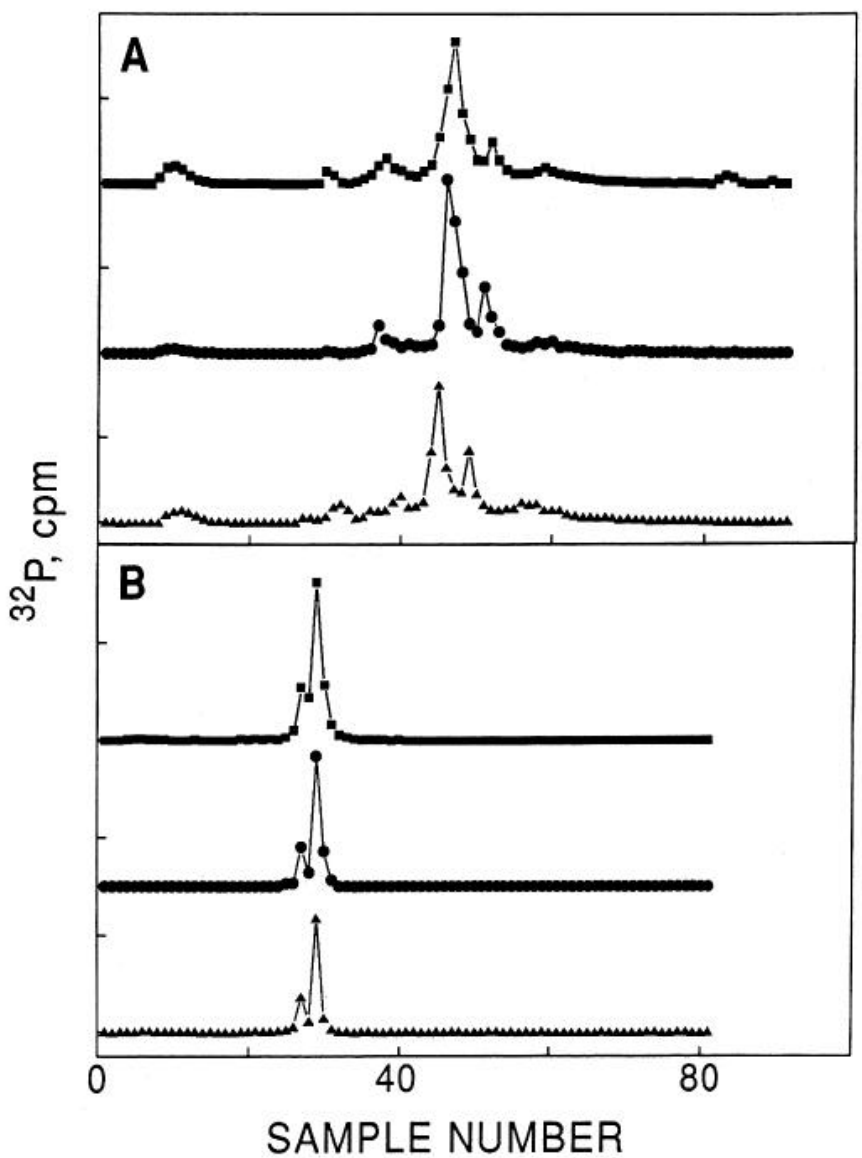

Figure 5. Comparison of the HPLC peptide maps of chymotryptic digests of purified peak-III GAD from rat brain $(\square)$, the $63-\mathrm{kDa}$ band from synaptosomes $(\bullet)$, and the $63-\mathrm{kDa}$ band from hippocampus $(\boldsymbol{\Delta})$. $A$, A chymotryptic digest of each sample was chromatographed on a sulfopropyl cation exchange column. $B$, Reverse-phase chromatography of the major peak of radioactivity from the cation-exchange chromatography of each sample in $A$. Samples from each peak were applied directly to a PepRPC C18 column (Pharmacia). Chromatography was carried out as described previously (Martin et al., 1990a). In both $A$ and $B$, each tick mark on the ordinate indicates a step of $2000 \mathrm{cpm}$. Baseline values for each chromatogram were about equal to background $(20 \mathrm{cpm})$. Plots of peak-III GAD and the 63-kDa bands from hippocampus and synaptosomes were offset to separate the chromatograms.

63-kDa protein is GAD. The labeled protein has the same apparent molecular weight as one of the forms of GAD purified from rat brain (Martin et al., 1990a), and immunoblotting showed that the position of the labeled protein on SDS-PAGE coincides exactly with the protein stained by the GAD- 6 and 1440 antiGAD antibodies. The labeled $63-\mathrm{kDa}$ protein is recognized by the GAD-1 monoclonal antibody to GAD as shown by immunoaffinity chromatography experiments. Labeling of this protein by ${ }^{32} \mathrm{P}$-pyridoxal-P is blocked by deoxypyridoxine- $\mathrm{P}$, a competitive inhibitor of the activation of apoGAD by pyridoxal-P (Martin et al., 1990a). Peptide mapping by HPLC indicates that the labeled peptide in the $63-\mathrm{kDa}$ protein is the same as the labeled active-site peptide of purified GAD. Finally, the labeled 63-kDa band cannot be attributed to any of several other pyridoxal-P-dependent enzymes because their subunit molecular weights differ substantially. These include GABA transaminase (50-58 kDa; Schousboe et al., 1973; Maitre et al., 1975; Churchich and Moses, 1981), aromatic amino acid decarboxylase (56 
kDa; Dominici et al., 1987), cysteine sulfinate decarboxylase (51 kDa; Tappaz et al., 1990), histidine decarboxylase $(55 \mathrm{kDa}$; Martin and Bishop, 1986), ornithine decarboxylase (52-54 kDa; Kitani and Fujisawa, 1988), pyridoxal kinase (40 kDa; Kwok et al., 1986), aspartate aminotransferase (46 kDa; Ovchinnikov et al., 1972), alanine aminotransferase (50 kDa; Saier and Jenkins, 1967), glutamine transaminase (51 kDa; Cooper and Meister, 1972), and glycogen phosphorylase (95 kDa; Seery et al., 1967).

Because the intensely labeled $63-\mathrm{kDa}$ band is the band most strongly stained by the GAD- 6 and 1440 antibodies, we conclude that the majority of endogenous apoGAD in brain corresponds to the product of the message for the $65-\mathrm{kDa}$ form of GAD cloned by Erlander et al. (1991), the peak-III $(\delta)$ form of GAD characterized by Spink et al. (1987) and Martin et al. (1990a), the lower-molecular-weight form of the two recognized by Legay et al. (1986, 1987), and the 59-kDa form of GAD of Chang and Gottlieb (1988).

We also observed labeling of a protein with a somewhat higher apparent molecular weight $(65.7 \pm 0.6 \mathrm{kDa})$ that is similar to that predicted from the cDNA for $\mathrm{GAD}_{67}$ (Kobayashi et al., 1987; Katarova et al., 1990; Wyborski et al., 1990). The labeled protein also coincided exactly with the bands stained most strongly by the K2 and 6799 antiGAD sera, and labeling was blocked by deoxypyridoxine-P. Thus, this labeled protein appears to be $\mathrm{GAD}_{67}$, though the evidence is somewhat weaker than that for $\mathrm{GAD}_{65}$. It appears likely, therefore, that some fraction of $\mathrm{GAD}_{67}$ is also present as apoenzyme, though the amount is much less than that of $\mathrm{GAD}_{65}$.

It has been reported that brain contains GAD subunits with apparent $M_{r}$ s of 40- and 80-kDa (Denner et al., 1987), and a gene coding for an $80-\mathrm{kDa}$ form of GAD has been reported (IIuang et al., 1990). The amino acid sequence predicted from this gene has very little homology with the sequences predicted from the genes for $\mathrm{GAD}_{65}$ or $\mathrm{GAD}_{67}$. We did not observe intense labeling of either 40 - or $80-\mathrm{kDa}$ proteins in synaptosomes or brain punches, indicating that these forms of GAD are not major contributors to the total apoGAD content of rat brain.

ApoGAD appears to play an important role in the regulation of GAD activity and, therefore, the regulation of GABA synthesis in brain (Martin, 1987). The interconversion of apo- and holoGAD has been studied in detail and is a highly regulated process (Porter and Martin, 1984, 1986; Porter et al., 1985, 1986; Spink et al., 1985; Martin, 1987). ApoGAD is formed by an alternative transamination reaction catalyzed by GAD that leads to the production of succinic semialdehyde and pyridoxamine 5 '-phosphate instead of the normal product, GABA. HoloGAD is formed by a two-step reaction of apoGAD with pyridoxal-P. The balance between apo- and holoGAD depends on the relative rates of the transamination and reactivation reactions, which are strongly influenced by $A T P$ and $P_{i}$ (Meeley and Martin, 1983a,b). ATP inhibits the activation of apoGAD and shifts the balance toward apoGAD, while $P_{i}$ opposes the inhibition by ATP and shifts the balance toward holoGAD. In tissue, the concentrations of ATP and $\mathrm{P}_{i}$ appear to favor the presence of high levels of apoGAD.

The earliest evidence for the presence of two forms of GAD that interact differently with pyridoxal-P was reported by Tapia and Sandoval (1971), who obtained kinetic evidence in tissue homogenates for the presence of two types of active sites. Others subsequently separated forms of GAD that differed markedly in their interactions with pyridoxal-P (Denner and $\mathrm{Wu}, 1985$;
Porter ct al., 1985; Spink ct al., 1985, 1987). The most detailed studies of the interaction of GAD and pyridoxal-P have been done with the pig brain enzyme (Porter et al., 1985; Spink et al., 1985), but it is clear that $\mathrm{GAD}_{65}$ from rat brain also undergoes the cyclic interconversion of apo- and holoGAD described above (Spink et al., 1987; Martin et al., 1990a). Bacterially expressed $\mathrm{GAD}_{65}$ from rat brain also appears to be more dependent on added pyridoxal-P than is GAD $_{67}$ (Erlander et al., 1991). A detailed comparison of the regulatory properties and the levels of expression of the two forms of rat brain GAD is required in order to explain fully the association of much larger amounts of apoGAD with the smaller than with the larger form of GAD. Even so, the information available on differences in the apparent regulatory properties of the multiple forms suggests that the two forms may be regulated differently in vivo.

Labeling with pyridoxal-P produces a remarkably simple pattern of labeling when studicd by SDS-PAGE. This simplicity is particularly striking in synaptosomes, where almost all of the labeling is associated with two proteins: GAD and the unidentified $30-\mathrm{kDa}$ protein. In punches, proteins in the $69-71-\mathrm{kDa}$ region were also intensely labeled, but labeling was relatively weak in the $40-58-\mathrm{kDa}$ region, where other pyridoxal-P-dependent enzymes should be located. The failure of deoxypyridoxine-P to inhibit the labeling of the 30- and 69-71-kDa proteins suggests that ${ }^{32} \mathrm{P}$-pyridoxal-P does not label these proteins in a specific pyridoxal-P binding site. Indeed, the much greater intensity of deoxypyridoxine- $P$-sensitive labeling at $63 \mathrm{kDa}$ than at any other molecular weight suggests that GAD is unusual if not unique in being present in large amounts as apoenzyme.

\section{References}

Chang Y-C, Gottlieb DI (1988) Characterization of the proteins purified with monoclonal antibodies to glutamic acid decarboxylase. J Neurosci 8:2123-2130.

Churchich JF, Moses U (1981) 4-Aminobutyrate aminotransferase: the presence of nonequivalent binding sites. J Biol Chem 256:1 1011104.

Cooper $\Lambda J L$, Meister A (1972) Isolation and properties of highly purified glutamine transaminase. Biochemistry 11:661-671.

Denner LA, Wu J-Y (1985) Two forms of rat brain glutamic acid decarboxylase differ in their dependence on free pyridoxal phosphate. J Neurochem 44:957-965.

Denner LA, Wei SC, Lin CT, Wu J-Y (1987) Brain L-glutamate decarboxylase: purification and subunit structure. Proc Natl Acad Sci USA 84:668-672.

Dominici P, Tancini B, Barra D, Voltattorni CB (1987) Purification and characterization of rat-liver 3,4-dihydroxyphenylalanine decarboxylase. Eur J Biochem 169:209-213.

Erlander MG, Tillakaratne NJK, Feldblum S, Patel N, Tohin AJ (1991) Two genes encode distinct glutamate decarboxylases. Neuron, in press.

Gottlieb DI, Chang Y-C, Schwob JE (1986) Monoclonal antibodies to glutamic acid decarboxylase. Proc Natl Acad Sci USA 83:88088812 .

Huang W-M, Reed-Fourquet L, Wu E, Wu J-Y (1990) Molecular cloning and amino acid sequence of brain L-glutamate decarboxylase. Proc Natl Acad Sci USA 87:8491-8495.

Itoh M, Uchimura H (1981) Regional differences in cofactor saturation of glutamate decarboxylase (GAD) in discrete brain nuclei of the rat. Effect of repeated administration of haloperidol on GAD activity in substantia nigra. Neurochem Res 6:1283-1289.

Katarova Z, Szabo G, Mugnaini E, Greenspan RJ (1990) Molecular identification of the $62 \mathrm{kd}$ form of glutamic acid decarboxylase from the mouse. Eur J Neurosci 2:190-202.

Kaufman DL, McGinnis JF, Krieger NR, Tobin AJ (1986) Brain glutamate decarboxylase cloned in $\lambda \mathrm{gt}-11$ : fusion protein produces $\gamma$-aminobutyric acid. Science 232:1138-1140.

Kaufman DL, Houser CR, Tobin AJ (1991) Two forms of the $\gamma$-aminobutyric acid synthetic enzyme glutamate decarboxylase have 
distinct intraneuronal distributions and cofactor interactions. J Neurochem 56:720-723.

Kitani T, Fujisawa H (1988) Strain-specific occurrence of two ornithine decarboxylase species in mouse kidney. Biochem Biophys Res Commun 151:450-457.

Kobayashi Y, Kaufman DL, Tobin AJ (1987) Glutamic acid decarboxylase cDNA: nucleotide sequence encoding an enzymatically active fusion protein. J Neurosci 7:2768-2772.

Kwok F, Kerry JA, Churchich JE (1986) Sheep brain pyridoxal kinase: fluorescence spectroscopy of the dimeric enzyme. Biochim Biophys Acta 874:167-173.

Legay F, Pelhate S, Tappaz ML (1986) Phylogenesis of brain glutamic acid decarboxylase from vertebrates: immunochemical studies. J Neurochem 46:1478-1486.

Legay F, Henry S, Tappaz M (1987) Evidence for two distinct forms of native glutamic acid decarboxylase in rat brain soluble extract: an immunoblotting study. J Neurochem 48:1022-1026.

Loscher W, Bohme G, Muller F, Pagliusi S (1985) Improved method for isolating synaptosomes from 11 regions of one rat brain: electron microscopic and biochemical characterization and use in the study of drug effects on nerve terminal $\gamma$-aminobutyric acid in vivo. J Neurochem 45:879-889.

Maitre M, Ciesielski L, Cash C, Mandel P (1975) Purification and studies on some properties of the 4-aminobutyrate: 2-oxoglutarate transaminase from rat brain. Eur J Biochem 52:157-169.

Martin DL (1987) Regulatory properties of brain glutamate decarboxylase. Cell Mol Neurobiol 7:237-253.

Martin DL, Wu SJ, Martin SB (1990a) Glutamate-dependent activesite labeling of brain glutamate decarboxylase. J Neurochem 55:524532.

Martin DL, Martin SB, Wu SJ, Espina N (1990b) The apoenzyme of GAD is present predominantly as the $63-\mathrm{kDa}$ form of GAD in synaptosomes and rat brain. Soc Neurosci Abstr 16:213.

Martin SAM, Bishop JO (1986) Purification and characterization of histidine decarboxylase from mouse kidney. Biochem J 234:349-354.

Meeley MP, Martin DL (1983a) Inactivation of brain glutamate decarboxylase and the effects of adenosine 5 '-triphosphate and inorganic phosphate. Cell Mol Neurobiol 3:39-54.

Meeley MP, Martin DL (1983b) Reactivation of substrate-inactivated brain glutamate decarboxylase. Cell Mol Neurobiol 3:55-68.

Miller LP, Walters JR, Martin DL (1977) Post-mortem changes implicate adenine nucleotides and pyridoxal-5'-phosphate in regulation of brain glutamate decarboxylase. Nature 266:847-848.

Miller LP, Walters JR, Eng N, Martin DL (1980) Glutamate holodecarboxylase levels and the regulation of GABA synthesis. Brain Res Bull [Suppl 2] 5:89-94.

Oertel WH, Schmechel DE, Tappaz ML, Kopin I (1981a) Production of a specific antiserum to rat brain glutamic acid decarboxylase by injection of an antigen-antibody complex. Neuroscience 6:2689-2700.

Oertel WH, Schmechel DE, Mugnaini E, Tappaz ML, Kopin IJ (1981b) Immunocytochemical localization of glutamate decarboxylase in rat cerebellum with a new antiserum. Neuroscience 6:2715-2735.
Ovchinnikov YA, Egorov CA, Aldanova NA, Feigina MY, I ipkin VM, Abdulaev NG, Grishin EV, Kiselev AP, Modyanov NN, Braunstein AE, Polyanovsky OL, Nosikov VV (1972) The complete amino acid sequence of cytoplasmic aspartatc amino transferase from pig heart. FEBS Lett 29:31-34.

Palkovits M, Brownstein MJ (1988) Maps and guide to microdissection of the rat brain, pp 1-223. Amsterdam: Elsevier.

Porter TG, Martin DL (1984) Evidence for feedback regulation of glutamate decarboxylase by $\gamma$-aminobutyric acid. J Neurochem 43 : 1464-1467.

Porter TG, Martin DL (1986) Non-steady-state kinetics of brain glutamate decarboxylase resulting from interconversion of the apo- and holoenzyme. Biochim Biophys Acta 874:235-244.

Porter TG, Spink DC, Martin SB, Martin DL (1985) Transaminations catalysed by brain glutamate decarboxylase. Biochem $\mathrm{J}$ 231:705-712.

Porter TG, Martin SB, Martin DL (1986) Activation of glutamate apodecarboxylase by succinic semialdehyde and pyridoxamine $5^{\prime}$-phosphate. J Neurochem 47:468-471.

Saier MH, Jenkins WT (1967) Alanine aminotransferase. I. Purification and properties. J Biol Chem 242:91-100.

Schousboe A, Wu J-Y, Roberts E (1973) Purification and characterization of the 4-aminobutyrate-2-ketoglutarate transaminase from mouse brain. Biochemistry 12:2868-2873.

Seery VL, Fischer EH, Teller DC (1967) A reinvestigation of the molecular weight of glycogen phosphorylase. Biochemistry 6:33153327.

Spink DC, Martin DL (1983) Multiple forms of glutamate decarboxylase in hog, rat, and human brain. In: Glutamate, glutamine and GABA in the central nervous system (Hertz L, Kvamme E, McGeer EG, Schousboe A, eds), pp 129-143. New York: Liss.

Spink DC, Wu SJ, Martin DL (1983) Multiple forms of glutamate decarboxylase in porcine brain. J Neurochem 40:1113-1119.

Spink DC, Porter TG, Wu SJ, Martin DL (1985) Characterization of three kinetically distinct forms of glutamate decarboxylase from pig brain. Biochem J 231:695-703.

Spink DC, Porter TG, Wu SJ, Martin DL (1987) Kinetically different, multiple forms of glutamate decarboxylase in rat brain. Brain Res 421:235-244.

Tapia R, Sandoval ME (1971) Study on the inhibition of brain glutamate decarboxylase by pyridoxal phosphate oxime- $O$-acetic acid. J Neurochem 18:2051-2059.

Tappaz M, Legay F, Almarghini K, Henry S, Remy A (1990) Cysteine sulfinic acid decarboxylases (CSD) in the brain. In: Taurine: functional neurochemistry, physiology, and cardiology (Pasantes-Morales $\mathbf{H}$, Martin DL, Shain W, Martin del Rio R, eds), pp 53-68. New York: Wiley-Liss.

Towbin H, Staehlin T, Gordon J (1979) Electrophoretic transfer of proteins from polyacrylamide gels to nitrocellulose sheets: procedure and some applications. Proc Natl Acad Sci USA 76:4350-4354.

Wyborski RJ, Bond RW, Gottlieb DI (1990) Characterization of a cDNA coding for rat glutamic acid decarboxylase. Mol Brain Res 8: 193-198. 